\title{
Flexibility at the margin and labor market volatility in OECD countries*
}

\author{
Hector Sala \\ Universitat Autònoma de Barcelona ${ }^{\dagger}$ \\ and IZA
}

\author{
José I. Silva \\ Universitat Autònoma de Barcelona ${ }^{\ddagger}$
}

Manuel E. Toledo

Universidad Carlos III de Madrid ${ }^{\S}$

\begin{abstract}
We argue that segmented labor markets with flexibility at the margin (e.g., just affecting fixed-term employees) may achieve similar volatility than fully deregulated labor markets. Flexibility at the margin produces a gap in separation costs among matched workers that cause fixed-term employment to be the main workforce adjustment device. Moreover, in the presence of limitations in the duration and number of renewals of fixed-term contracts, firms respond by fostering labor turnover which further raises the volatility of the labor market. We present a matching model with temporary and permanent jobs where (i) the gap in firing costs and (ii) restrictions in the use of fixedterm contracts play the central role to explain the similar volatility observed in many regulated labor markets with flexibility at the margin vis-à-vis the fully deregulated ones.
\end{abstract}

JEL Classification: J23, J41, J63.

Keywords: flexibility at the margin, volatility, separation costs, matching model.

\footnotetext{
* Hector Sala is grateful to the Spanish Ministry of Education and Science for financial support through grant SEJ2006-14849/ECON.

† Departament d'Economia Aplicada, Universitat Autònoma de Barcelona, 08193 Bellaterra, Spain; tel.: + 3493 5812779; email: hector.sala@uab.es. Correspondence address.

‡ Departament d'Economia Aplicada, Universitat Autònoma de Barcelona, Edifici B, 08193 Bellaterra, Spain; tel: + 3493 5811680;. e-mail: joseignacio.silva@uab.es.

$\S$ Departamento de Economía, Universidad Carlos III de Madrid, Calle Madrid 126, 28903 Getafe, Spain;tel: + 3491 6249791; e-mail: matoledo@eco.uc3m.es
} 


\section{Introduction}

Azariadis and Pissarides (2007) have recently argued that unemployment volatility is magnified by international capital mobility. Our claim is that it is also increased by the legislative setup. Capital mobility and market (de)regulation are two sides of the same coin, the coin of a globalization process entailing endless needs of flexibility. This flexibility, however, is not uniform neither across nor within markets.

This paper argues that flexibility at the margin is a sufficient device to achieve the quick adjustments and large volatilities that characterize flexible labor markets such as the AngloSaxon ones. This is an important matter because it helps to explain why some regulated labor markets, such as the Spanish one, display similar volatility than the Anglo-Saxon ones. Specifically, we argue that the gap in the separation costs between temporary/fixed-term employees and permanent/regular employees provides a crucial amplification mechanism of labor market volatility. This gap helps generate a large share of temporary contracts which are used by firms as the main workforce adjustment device. Hence the term flexibility at the margin (see Malo and Toharia, 2000). Moreover, in the presence of limitations in the duration and number of renewals of fixed-term contracts, firms respond by fostering labor turnover which further increases the volatility of the labor market.

Table 1 offers crucial information to allow a differentiation of two types of labor market that characterize many OECD economies. First, the well-known Anglo-Saxon type, which is characterized by a small degree of Employment Protection Legislation (EPL) in regular contracts, and no limitations on the renewal and duration of temporary contracts -which we denote by $[\mathrm{NL}]$ in Table 1-. As a consequence of the high flexibility in the regular segment of the market, there is a small use of temporary contracts like in Canada (6.9\%), Ireland (7.4\%), UK (6.3\%) and US (4.5\%).

Second, the flexibility-at-the-margin type, which combines a high degree of employment protection in the regular segment with a limited flexibility in the use of temporary contracts -which we denote by [L] in Table 1-. Economies such as Portugal, Sweden and Spain are among the ones with the highest values of the EPL index (4.3, 2.9 and 2.6, respectively) and display the highest temporary shares $(15.8 \%, 15.1 \%$ and $32.3 \%)$.

It is well known that fixed-term employment contracts have been introduced in a number of European countries as a way to provide flexibility to economies with high employment protection levels. Nevertheless, the implementation of temporary contracts have typically included restrictions such as limited renewals or maximum durations. ${ }^{1}$ For example, the Spanish 1984 labor market reform crucially broadened the scope of fixed-term contracts while, at the same time, restricted to 3 the maximum number of successive contracts with a top accumulated duration of 2 years (OECD, 2004). In Portugal, temporary contracts

\footnotetext{
${ }^{1}$ For a comprehensive overview of such restrictions, see OECD (2004).
} 
can also be renewed 3 times, but with a longer maximum duration of 30 months. These limitations provide a great source of labor turnover and, thus, of labor market volatility. For example, unemployment volatilities in Portugal and Sweden are $12.1 \%$ and $16.2 \%$, well above those of US and UK (8.7\% and 7.0\%). In turn, the unemployment volatility in Spain $(7.8 \%)$ falls between these two deregulated countries. In other words, the flexibility at the margin may be important in the achievement of the quick adjustments and high volatilities that characterize the Anglo-Saxon labor markets.

\begin{tabular}{|c|c|c|c|c|c|c|}
\hline & \multicolumn{4}{|c|}{ Legislation } & \multirow{2}{*}{$\begin{array}{c}\text { Capital } \\
\text { mobility } \\
\text { FDI/DI } \\
{[E]}\end{array}$} & \multirow{2}{*}{$\begin{array}{c}\text { Volatility } \\
\text { s.d. (u) } \\
{[F]}\end{array}$} \\
\hline & $\begin{array}{c}\text { Restrictions } \\
\text { on TCs } \\
{[A]}\end{array}$ & $\begin{array}{c}\text { EPL } \\
\text { on PCs } \\
{[B]}\end{array}$ & $\begin{array}{c}\text { Share } \\
{[C]}\end{array}$ & $\begin{array}{c}\text { Conversion } \\
\text { rate } \\
{[D]} \\
\end{array}$ & & \\
\hline Belgium & {$[\mathrm{L}]$} & 1.7 & 6.9 & 42.7 & 26.1 & 8.4 \\
\hline Canada & [NL] & 1.3 & 12.3 & n.a & 6.6 & 6.6 \\
\hline Denmark & {$[\mathrm{L}]$} & 1.5 & 10.6 & 45.4 & 8.6 & 8.2 \\
\hline Finland & {$[\mathrm{L}]$} & 2.3 & 16.8 & 38.5 & 6.8 & 16.2 \\
\hline France & {$[\mathrm{L}]$} & 2.3 & 12.6 & 20.8 & 8.4 & 5.3 \\
\hline Germany & {$[\mathrm{L}]$} & 2.7 & 11.4 & 40.6 & 0.6 & 10.9 \\
\hline Ireland & {$[\mathrm{NL}]$} & 1.6 & 7.4 & 47.0 & 15.8 & 8.7 \\
\hline Italy & {$[\mathrm{L}]$} & 1.8 & 8.2 & 41.3 & 2.0 & 3.9 \\
\hline Japan & [NL] & 2.4 & 11.6 & n.a & 0.3 & 5.4 \\
\hline Netherlands & {$[\mathrm{L}]$} & 3.1 & 11.8 & 49.1 & 12.6 & 12.5 \\
\hline Spain & {$[\mathrm{L}]$} & 2.6 & 32.3 & 23.1 & 7.7 & 7.8 \\
\hline Sweden & {$[\mathrm{L}]$} & 2.9 & 15.1 & n.a & 20.9 & 16.2 \\
\hline UK & {$[\mathrm{NL}]$} & 0.9 & 6.3 & 56.1 & 12.1 & 7.0 \\
\hline US & {$[\mathrm{NL}]$} & 0.2 & 4.5 & n.a & 1.5 & 8.7 \\
\hline Portugal & {$[\mathrm{L}]$} & 4.3 & 15.8 & 39.0 & 5.8 & 12.1 \\
\hline \multirow{2}{*}{\multicolumn{2}{|c|}{$\begin{array}{l}\text { Average }[\mathrm{L}] \text { countries } \\
\text { Average }[\mathrm{NL}] \text { countries }\end{array}$}} & 2.5 & 14.2 & 37.8 & 10.0 & 10.2 \\
\hline & & 1.3 & 8.4 & 51.6 & 7.2 & 7.3 \\
\hline \multicolumn{7}{|c|}{$\begin{array}{l}\text { Notes: [A] refers to limited renewals and a maximum duration of temporary contracts } \\
\text { (TCs); [NL] stands for No Limitations, [L] for Limitations; [B] refers to an EPL index } \\
\text { on permanent contracts (PCs) in the late 1990s; [C] to the share of TCs in 1999-2003; } \\
\text { [D] to the conversion rate from TCs to PCs in 1996-1997; [E] to the ratio of Foreign } \\
\text { Direct Investment (FDI) inflows to Domestic Investment (DI) in 1992-1997; } \\
\text { [F] to the standard deviation (s.d.) of standardized unemployment in 1990:1 to 2005:4. } \\
\text { Sources: [A] OECD (2004); [B] Azariadis and Pissarides (2007); } \\
\text { [C] OECD (2006); [D] OECD (2002); [E] OECD Main Economic Indicators (2007). }\end{array}$} \\
\hline
\end{tabular}

To further check to what extent this is a promising hypothesis, Table 1 also provides the averages by countries with and without restrictions on temporary contracts. Observe 
that the first group has a substantially higher index of EPL (2.5 versus 1.3) and a higher share of temporary contracts (14.2\% versus $8.4 \%)$, while it achieves a larger unemployment volatility (10.2 versus 7.3). Thus, despite the Anglo-Saxon labor markets have a less stringent legislation, unemployment in segmented/dual labor markets with restrictive EPL and high firing costs in the regular side is, on average, $40 \%$ more volatile.

\begin{tabular}{|c|c|c|c|c|}
\hline & $\begin{array}{c}\text { EPL } \\
\text { on PCs } \\
{[B]} \\
\end{array}$ & $\begin{array}{c}\text { Share } \\
{[C]}\end{array}$ & $\begin{array}{c}\text { Conversion } \\
\text { rate } \\
{[D]}\end{array}$ & $\begin{array}{c}\mathrm{FDI} / \mathrm{DI} \\
{[E]}\end{array}$ \\
\hline All countries & 0.45 & 0.23 & 0.18 & 0.30 \\
\hline Countries with restrictions on TCs $[\mathrm{L}]$ & 0.47 & 0.14 & 0.37 & 0.25 \\
\hline
\end{tabular}

Table 2 takes a step forward in this analysis by providing the correlation matrix of unemployment volatilities in the OECD countries with some legislation items and capital mobility. The main result here is the positive correlation with EPL on regular contracts, which amounts to 0.45 and is higher than the 0.30 correlation with international mobility in capital emphasized by Azariadis and Pissarides (2007). Even though the positive association of the conversion rate from temporary to permanent jobs, with a coefficient of 0.18 , is also remarkable, the second main result refers to this coefficient in the specific case of countries where employment protection and temporary contracts renewal limitations coexist. In this case, the correlation coefficient attains a remarkable 0.37 .

These results suggest that the analysis of labor markets with flexibility at the margin may yield important lessons for economies currently involved in labor market institutional reforms. This paper is a step in this direction. In particular, this paper contributes to the understanding of the sources of unemployment volatility by assessing the role played by (i) the gap between the separation costs of the fixed-term and permanent employees; and (ii) restrictions in the use of temporary contracts. We claim that these are two important driving forces behind the volatility achieved by segmented labor markets.

To evaluate the business cycle implications associated with the presence of temporary employment we extend the equilibrium matching model of Mortensen and Pissarides (1994) by introducing the possibility that firms hire workers on a fixed-term basis. We, thus, differentiate between permanent and temporary employees, where the latter have fixedterm contracts and virtually zero firing costs. Fixed-term contracts have a limited duration by definition and many countries have introduced legal restrictions on their use in the form of a maximum number of renewals. When this maximum is reached, firms are bounded to convert them into permanent contracts, with higher firing costs, and change the status of the worker. To avoid this restriction, however, firms have the alternative to finish that 
temporary relationship and hire a new temporary worker. Our theoretical model features these restrictions. Since many OECD countries show a high degree of employment protection in regular jobs and limited flexibility in the use of temporary ones (see Table 1) we find this model particularly suitable to study the incidence of flexibility at the margin on labor market volatility.

Our formal analysis draws on a widely accepted distinction between entrants (or outsiders) and insiders (see Lindbeck and Snower, 1989), which is not new either in the matching literature (see for example Wasmer, 1999; Blanchard and Landier, 2002; Kugler et al., 2002; Cahuc and Postel-Vinay, 2002; Osuna, 2005). However, in contrast with the long-run perspective generally taken by previous studies, this paper differs in scope and focuses exclusively on business cycle fluctuations. Our paper also differs from Boeri and Garibaldi (2007), who focus on the transitional dynamics of EPL reforms providing flexibility 'at the margin'.

The simulated results provide new insights on the effects of different EPL schemes on the cyclical behavior of job creation, job destruction and unemployment. More precisely, the main results stem from considering these effects in a situation with flexibility at the margin in which, we show, the gaps in separation costs between temporary and permanent jobs and the restricted use of fixed-term contracts increase the labor market volatility. To avoid transitions to a permanent status which entails future costs in case of adjustments, firms' workforce adjustments take place more intensively and with higher frequency in temporary jobs. In particular, rather than converting fixed-term contracts into permanent, firms will tend to fire 'old' temporary workers and hire new ones not yet affected by the legal conversion restriction. Thus, a situation of flexibility at the margin with restrictions generates a large volatility in the job creation, job destruction and unemployment rates in response to productivity shocks.

In contrast, when flexibility at the margin is suppressed, most of the volatility in our model vanishes and gives rise to a scenario similar to that before the explosion of the fixedterm contracts in many OECD countries. This situation corresponds to the one in the aftermath of the labor market reforms that took place since the middle of the 1980s in several of these economies. In short, this paper provides an evaluation of some of the pros and cons of this type of reforms and gives some policy insights for those countries currently seeking to foster the flexibility of their labor markets.

A final important result is the almost perfect negative correlation we find between job reallocation and the business cycle both in fully deregulated and flexibility-at-the-margin labor market types. This result clarifies a similar empirical finding for Spain in Messina and Valanti (2007) and helps to explain why the job turnover rate of some regulated labor markets displays a countercyclical behavior in contrast to the acyclical or even procyclical movements suggested by some studies (Garibaldi, 1998). 
The remaining of the paper is structured as follows. Section 2 presents the model, which is calibrated in Section 3 and simulated in Section 4. Section 5 concludes.

\section{The model}

The economy is integrated by a continuum of risk-neutral, infinitely-lived workers and firms, which discount future payoffs at a common rate $\beta$. We further assume that capital markets are perfect.

Workers can either be employed or unemployed. Those who are employed can be so either on a temporary basis $(T)$, or on a permanent one $(P)$. When finding a job, unemployed workers become temporary and only from there may be upgraded to permanent with probability $\iota$. The productivity of the match is a function of aggregate productivity $A_{t}$, and a term $z_{t}$ idiosyncratic to the match. There is a firm-specific productivity term independent and identically distributed across firms and time, with a cumulative distribution function $G(z)$ and support $[0, \bar{z}]$.

There is a time-consuming and costly process of matching workers and job vacancies, captured by a constant-returns-to-scale matching function $m\left(u_{t}, v_{t}\right)$, where $u_{t}$ denotes the unemployment rate and $v_{t}$ is the vacancy rate. Unemployed workers meet jobs with probability $f\left(\theta_{t}\right)$ whereas vacancies meet workers with probability $q\left(\theta_{t}\right)$. From the properties of the matching function, these probabilities only depend on the vacancy-unemployment ratio $\theta_{t}$, where the higher the number of vacancies with respect to the number of unemployed workers, the easier to find a job and the more difficult to fill up vacancies.

Firms have a constant-returns-to-scale production technology with labor as an only input. A posted job can either be filled or vacant. The firm has to open a job vacancy entailing cost $c$ per period before a position can be filled. Each productive match yields an instantaneous profit equal to the difference between labor productivity and the wage, which is $A_{t} z_{t}-w_{t}^{T}\left(z_{t}\right)$ for a temporary position and $A_{t} z_{t}-w_{t}^{P}\left(z_{t}\right)$ for a permanent one.

When a match with a temporary job is terminated, the firm pays a firing $\operatorname{tax} \gamma^{T}$, which is assumed to be fully wasted and lower or equal than the firing tax for a permanent position, $\gamma^{P}$. Due to legal restrictions, after renewing a number of times a fixed-term contract, firms are bounded to convert it into permanent. We abstract from the actual restrictions on the duration of temporary jobs and the number of renewals and, for simplicity, represent them by an exogenous conversion probability $\iota$. For instance, the tighter those restrictions are (i.e., shorter permitted maximum duration and/or fewer possible renewals), the higher $\iota$ is. To avoid these restrictions, however, firms have the alternative to finish that temporary relationship and hire a new worker. If a match is broken, either from a temporary or a permanent status, the firm opens a new vacancy.

Accordingly, the value of vacancies $\left(V_{t}\right)$ and filled positions, $J_{t}^{T}\left(z_{t}\right)$ and $J_{t}^{P}\left(z_{t}\right)$, are 
represented by the following Bellman equations:

$$
\begin{aligned}
V_{t}=-c+\beta E_{t}\left[q\left(\theta_{t}\right) \int_{\widetilde{z}_{t+1}^{I}}^{\infty} J_{t+1}^{T}(z) d G(z)+\left(1-q\left(\theta_{t}\right)\left(1-G\left(\widetilde{z}_{t+1}^{I}\right)\right) V_{t+1}\right],\right. \\
J_{t}^{T}\left(z_{t}\right)=A_{t} z_{t}-w_{t}^{T}\left(z_{t}\right)+\beta E_{t}\left[\iota\left(\int_{\widetilde{z}_{t+1}^{C}}^{\infty} J_{t+1}^{P}(z) d G(z)+G\left(\widetilde{z}_{t+1}^{C}\right)\left(V_{t+1}-\gamma^{T}\right)\right)\right. \\
\left.+(1-\iota)\left(\int_{\widetilde{z}_{t+1}^{T}}^{\infty} J_{t+1}^{T}(z) d G(z)+G\left(\widetilde{z}_{t+1}^{T}\right)\left(V_{t+1}-\gamma^{T}\right)\right)\right], \\
J_{t}^{P}\left(z_{t}\right)=A_{t} z_{t}-w_{t}^{P}\left(z_{t}\right)+\beta E_{t}\left[\int_{\widetilde{z}_{t+1}^{P}}^{\infty} J_{t+1}^{P}(z) d G(z)+G\left(\widetilde{z}_{t+1}^{P}\right)\left(V_{t+1}-\gamma^{P}\right)\right],
\end{aligned}
$$

where $\widetilde{z}^{j}, j=I, T, C, P$, are productivity thresholds defined such that nonprofitable matches (i.e., with negative surplus) are severed. ${ }^{2}$ Thus, the conditions defining these thresholds for temporary and permanent job destruction (also called reservation productivities) are:

$$
\begin{aligned}
J_{t}^{T}\left(\widetilde{z}_{t}^{I}\right)-V_{t} & =0, \\
J_{t}^{T}\left(\widetilde{z}_{t}^{T}\right)-V_{t}+\gamma^{T} & =0, \\
J_{t}^{P}\left(\widetilde{z}_{t}^{C}\right)-V_{t}+\gamma^{T} & =0, \\
J_{t}^{P}\left(\widetilde{z}_{t}^{P}\right)-V_{t}+\gamma^{P} & =0 .
\end{aligned}
$$

Condition (4) refers to those unemployed workers who have met a vacant job. Note that in this case the firm does not have to pay $\gamma^{T}$ in the absence of agreement. Expressions (5) and (7) define the reservation productivity for current temporary and permanent workers, respectively, whereas (6) refers to those temporary workers on the verge of becoming permanent. That is, those who were drawn with probability $\iota$. Recall that firms have the option to avoid temporary-to-permanent conversion by laying off workers before they must be offered a permanent contract due to legal restrictions. Hence, we need to consider the case where a firm does not want to offer a permanent contract to a temporary worker that has been randomly chosen to become permanent. Notice that in this case the firm is only liable to $\gamma^{T}$ if it chooses to break up the match.

Let $s_{t}^{I}=G\left(\widetilde{z}_{t}^{I}\right)$ and $s_{t}^{C}=G\left(\widetilde{z}_{t}^{C}\right)$. It follows that the temporary and permanent matches separate with probabilities $s_{t}^{T}=(1-\iota) G\left(\widetilde{z}_{t}^{T}\right)+\iota s_{t}^{C}$ and $s_{t}^{P}=G\left(\widetilde{z}_{t}^{P}\right)$, respectively. Moreover, job creation takes place with probability $q\left(\theta_{t}\right)\left(1-s_{t}^{I}\right)$ when a firm and a worker meet and agree on an employment contract. Similarly, unemployed workers find a job with probability $f\left(\theta_{t}\right)\left(1-s_{t}^{I}\right)$.

At the workers' side the values of the different statuses - unemployed, $U_{t}$; temporary

\footnotetext{
${ }^{2}$ Since the value of a match is increasing in $z_{t}$, we can prove that there exists a threshold $\widetilde{z}_{t} \in[0, \bar{z}]$ below which matches are no longer profitable.
} 
employee, $W_{t}^{T}\left(z_{t}\right)$; and permanent employee, $W_{t}^{P}\left(z_{t}\right)$ - are given by the following expressions:

$$
\begin{aligned}
U_{t}=b+\beta E_{t}\left[f\left(\theta_{t}\right) \int_{\widetilde{z}_{t+1}^{I}}^{\infty} W_{t+1}^{T}(z) d G(z)+\left(1-f\left(\theta_{t}\right)\left(1-G\left(\widetilde{z}_{t+1}^{I}\right)\right) U_{t+1}\right],\right. \\
W_{t}^{T}\left(z_{t}\right)=w_{t}^{T}\left(z_{t}\right)+\beta E_{t}\left[\iota\left(\int_{\widetilde{z}_{t+1}^{C}}^{\infty} W_{t+1}^{P}(z) d G(z)+G\left(\widetilde{z}_{t+1}^{C}\right) U_{t+1}\right)\right. \\
\left.+(1-\iota)\left(\int_{\widetilde{z}_{t+1}^{T}}^{\infty} W_{t+1}^{T}(z) d G(z)+G\left(\widetilde{z}_{t+1}^{T}\right) U_{t+1}\right)\right], \\
W_{t}^{P}\left(z_{t}\right)=w_{t}^{P}\left(z_{t}\right)+\beta E_{t}\left[\int_{\widetilde{z}_{t+1}^{P}}^{\infty} W_{t+1}^{P}(z) d G(z)+G\left(\widetilde{z}_{t+1}^{P}\right) U_{t+1}\right] .
\end{aligned}
$$

According to these equations, any unemployed worker gets a constant current value $b$ from leisure and finds job with probability $f\left(\theta_{t}\right)$. This worker becomes employed in a temporary job if a match takes place, and remains unemployed if not. Employed workers earn an endogenous wage $w_{t}^{T}\left(z_{t}\right)$ if temporary and $w_{t}^{P}\left(z_{t}\right)$ if permanent. If a match is broken either from a temporary or a permanent status, the worker becomes unemployed.

We also assume that there is free entry for firms. Hence firms open vacancies until the expected value of doing so becomes zero. Therefore, in equilibrium:

$$
V_{t}=0
$$

Furthermore, because neither workers nor employers can instantaneously find an alternative match partner in the labor market, and because hiring and firing decisions are costly, a match surplus exists. To divide this surplus we assume wages to be the result of bilateral Nash bargaining between workers and firms. They are revised every period upon the occurrence of new shocks, and the Nash solution is the wage that maximizes the weighted product of the workers' and the firms' net return from the job match. The first-order conditions for the temporary and permanent employees yield the following two equations:

$$
\begin{aligned}
& (1-\eta)\left(W_{t}^{T}\left(z_{t}\right)-U_{t}\right)=\eta\left(J_{t}^{T}\left(z_{t}\right)-V_{t}+\gamma^{T}\right), \\
& (1-\eta)\left(W_{t}^{P}\left(z_{t}\right)-U_{t}\right)=\eta\left(J_{t}^{P}\left(z_{t}\right)-V_{t}+\gamma^{P}\right),
\end{aligned}
$$

where $\eta \in(0,1)$ denotes the workers' bargaining power relative to firms. Note that the Nash conditions present terms depending on $\gamma^{T}$ and $\gamma^{P}$. Because separation costs are operational they are explicitly considered in the wage negotiation. This implies that the firms' threat point when negotiating with a worker is no longer the value of a vacancy $V_{t}$ but $\left(V_{t}-\gamma^{T}\right)$ or $\left(V_{t}-\gamma^{P}\right)$ depending on the type of worker.

To fully characterize the dynamics of the model economy, we need to define the law of motion for the unemployment rate $u_{t}$, and the mass of temporary and permanent workers, 
$n_{t}^{T}$ and $n_{t}^{P}$, respectively. These evolve according to the following difference equations:

$$
\begin{aligned}
u_{t} & =u_{t-1}+s_{t}^{T} n_{t-1}^{T}+s_{t}^{P} n_{t-1}^{P}-f\left(\theta_{t-1}\right)\left(1-s_{t}^{I}\right) u_{t-1}, \\
n_{t}^{T} & =n_{t-1}^{T}+f\left(\theta_{t-1}\right)\left(1-s_{t}^{I}\right) u_{t-1}-s_{t}^{T} n_{t-1}^{T}-\iota\left(1-s_{t}^{C}\right) n_{t-1}^{T}, \\
n_{t}^{P} & =n_{t-1}^{P}+\iota\left(1-s_{t}^{C}\right) n_{t-1}^{T}-s_{t}^{P} n_{t-1}^{P} .
\end{aligned}
$$

Moreover, we define the job creation rate $\left(j c_{t}\right)$ as new matches scaled by employment,

$$
j c_{t}=\frac{m\left(u_{t-1}, v_{t-1}\right)\left(1-s_{t}^{I}\right)}{\left(1-u_{t}\right)}
$$

whereas the job destruction rate $\left(j d_{t}\right)$ is equal to the average separation rate,

$$
j d_{t}=s_{t}=\frac{s_{t}^{T} n_{t-1}^{T}+s_{t}^{P} n_{t-1}^{P}}{\left(1-u_{t}\right)} .
$$

\section{Calibration}

We calibrate the model at quarterly frequency in order to match some steady-state moments for the US economy. As in den Haan et al. (2000), we set the job finding probability $f\left(\theta^{*}\right)(1-$ $\left.s^{*}\right)$ to 0.45 , the job filling probability $q\left(\theta^{*}\right)\left(1-s^{*}\right)$ to 0.71 , and the job separation rate $s^{*}$ to 0.10 (symbol ${ }^{*}$ denotes steady-state level). Substituting these values in equation (14), with $\dot{u}=0$, we obtain an average unemployment rate of $0.182 .{ }^{3}$ Similarly, the idiosyncratic productivity shocks are i.i.d. log-normally distributed with mean $\mu=0$ and standard deviation $\sigma=0.2$.

The steady-state aggregate labor productivity $A^{*}$ is normalized to one. The logarithm of this variable follows an $\mathrm{AR}(1)$ process such that $\log A_{t}=\rho \log A_{t-1}+\epsilon_{t}$. The values of the autoregressive parameter and the standard deviation of the white noise process, $\rho=0.95$ and $\sigma_{A}=0.0028$, have been calibrated to match the cyclical volatility of the US labor productivity between 1970 and $2004 .{ }^{4}$

The discount parameter $\beta$, and the worker bargaining parameter $\eta$ are set to 0.99 and 0.50, respectively. As in den Haan et al. (2000), we assume the matching function to be

$$
m\left(u_{t}, v_{t}\right)=\frac{u_{t} v_{t}}{\left(u_{t}^{\phi}+v_{t}^{\phi}\right)^{1 / \phi}}
$$

Given the values of the job finding and filling probabilities and the properties of the

\footnotetext{
${ }^{3}$ This unemployment rate is reasonable if we include those individuals registered as inactive that are actively searching for jobs. On this issue see, for example, Blanchard and Diamond (1989).

${ }^{4} \mathrm{As}$ in Shimer (2005), the average labor productivity is the seasonally adjusted real average output per person in the non-farm business sector, constructed by the Bureau of Labor Statistics (BLS) from the National Income and Product Accounts and the Current Employment Statistics. It is reported in logs as deviations from an HP trend with smoothing parameter 1600.
} 
matching function, the steady-state ratio of vacancies to unemployment $\theta^{*}=\frac{f\left(\theta^{*}\right)\left(1-s^{*}\right)}{q\left(\theta^{*}\right)\left(1-s^{*}\right)}$ is 0.634 , and the matching parameter $\phi$ is 1.637. Finally, the vacancy costs $c$ and the value of being unemployed $b$ are set to 0.099 and 0.963 , which ensures that in the steady state $j c=j d=0.10$.

\begin{tabular}{|c|c|c|c|}
\hline \multicolumn{4}{|c|}{ Table 3. Calibrated parameters for the baseline economy } \\
\hline \multicolumn{2}{|l|}{ Parameters } & Value & Source \\
\hline Ave. aggregate labor productivity & $A^{*}$ & 1 & Normalised \\
\hline Discount rate & $\beta$ & 0.99 & {$[\mathrm{~A}]$} \\
\hline Mean of $z$ & $\mu$ & 0 & {$[\mathrm{~A}]$} \\
\hline Standard deviation of $\mathrm{z}$ & $\sigma$ & 0.02 & {$[\mathrm{~A}]$} \\
\hline Persistence parameter of $A$ & $\rho$ & 0.95 & {$[\mathrm{~B}]$} \\
\hline Standard deviation of $A$ & $\sigma_{A}$ & 0.012 & [B] \\
\hline Discount rate & $\beta$ & 0.99 & {$[\mathrm{~A}]$} \\
\hline Workers' bargaining power & $\eta$ & 0.50 & {$[\mathrm{~A}]$} \\
\hline Parameter of the matching function & $\phi$ & 1.637 & {$[\mathrm{C}]$} \\
\hline Hiring costs & $c$ & 0.099 & {$[\mathrm{C}]$} \\
\hline Firing costs for temporary contracts & $\gamma^{T}$ & 0 & {$[\mathrm{~A}]$} \\
\hline Firing costs for permanent contracts & $\gamma^{P}$ & 0 & {$[\mathrm{~A}]$} \\
\hline Employment conversion rate & $\iota$ & 0 & {$[\mathrm{~A}]$} \\
\hline Leisure parameter & $b$ & 0.963 & {$[\mathrm{C}]$} \\
\hline $\begin{array}{ll}\text { Notes: } & \text { [A] Other studies, data or own asst } \\
& \text { [B] Set to match the cyclical behav } \\
& \text { [C] Obtained from theoretical mod }\end{array}$ & $\begin{array}{l}\text { mpti } \\
\text { or of } \\
\text { l. }\end{array}$ & $\begin{array}{l}\text { as expla } \\
\text { or produ }\end{array}$ & $\begin{array}{l}\text { d in main text } \\
\text { vity. }\end{array}$ \\
\hline
\end{tabular}

For the remaining parameters associated to restrictions in the labor market, $\gamma^{P}, \gamma^{T}$, and $\iota$, we consider several cases. Our baseline parameterization describes the US labor market, where there are hardly any legal restrictions as the ones studied in this paper. Thus, we set $\gamma^{P}=\gamma^{T}=0$. This implies the existence of just one type of job since temporary and permanent contracts become perfect substitutes. Hence $\iota$ becomes irrelevant. ${ }^{5}$

In next section we simulate different legislative scenarios, which we compare against this benchmark case. The objective of this exercise is to assess the effects of changes in the EPL on the labor market volatility. The first of these scenarios represents a situation with employment protection and no temporary contracts. This case considers that firms provide a single type of job. It attempts to mimic the situation of several OECD labor markets before the introduction of the temporary contracts and the development of fixed-term employment (a paradigmatic case would be Spain before its 1984 labor market reform). In terms of the model, this has two implications. First, firms are no longer able to make use of fixed-term contracts. As a consequence, we set $\gamma^{T}=\gamma^{P}=\gamma$, ruling out the distinction between

\footnotetext{
${ }^{5}$ When $\gamma^{P}=\gamma^{T}, \iota$ can take any value in $[0,1]$. We set it to zero. Similarly, since $\gamma^{P}=\gamma^{T}=0$, there is only one job destruction condition. Thus, $s_{t}=s_{t}^{T}=s_{t}^{P}=s_{t}^{C}=s_{t}^{I}$ for all $t$.
} 
temporary and permanent firing costs. The second implication is that the conversion rate from temporary to permanent contracts becomes irrelevant.

Another scenario presents a situation with employment protection and temporary contracts, which may be subject to restrictions in terms of duration and renewal limitations. This mimics the situation of most OECD countries in the aftermath of the partial labor market reforms implemented to introduce flexibility at the margin (again, the paradigmatic case is Spain after the 1984 labor market reform). Within this scenario, we distinguish between two cases:

1. We set $\gamma^{T}=0$ and consider different values for $\gamma^{P}>0$. Moreover, we fix $\iota=0.10$. This value is close to the average quarterly conversion rate observed in the OECD countries. In this context, we evaluate the effects of changes in the permanent-worker firing cost on the volatility of labor market outcomes.

2. We set $\gamma^{T}=0$ and $\gamma^{P}=0.15$, so that there is a gap of $15 \%$ in firing costs. As opposed to the previous case, this exercise keeps the gap in separation costs constant. However, here we consider a number of values for the conversion probability $\iota$ from 0 to 1 . Thus, for a given gap in separation costs, we evaluate the response of the labor market to different degrees of restrictions on the duration and renewal of temporary contracts.

\section{Simulation results}

For each simulation we create 1000 sample paths of 1140 quarters, throw away the first 1000 and keep the 140 quarters corresponding to 1970-2005; detrend the generated data using the HP filter with the smoothing parameter equal to 1600; and calculate the standard deviations of the relevant variables.

As we mentioned in the previous Section, we depart from the benchmark calibrated case, with no employment protection, and consider different analytical scenarios of labor market regulations. These scenarios stem from the values assigned to the legislative parameters: the firing tax parameters, $\gamma^{P}$ and $\gamma^{T}$, and $\iota$, which captures the existence of renewal restrictions in temporary contracts. When modifying these key parameters, we hold all the other ones constant and compute the new equilibrium values of the endogenous variables in the steady state. We then solve and simulate the model around the new steady state, and compute the second moments of the relevant variables.

\subsection{Employment protection and unemployment volatility}

These exercises provide new insights on the effects of different EPL schemes, in particular of a situation with flexibility-at-the-margin, on the cyclical behavior of job creation, job de- 
struction and unemployment. Table 4 summaries the results from the conducted simulations by distinguishing three analytical panels.

The first noteworthy result is the rising volatility of the $\mathrm{JC}$ rate in response to both higher firing costs and a larger conversion rate from temporary to permanent contracts. This is shown in the first column of Table 4. In the absence of temporary contracts (panel 1), when the firing tax is increased from $0 \%$ to $15 \%$, the volatility of the JC rate rises around $39 \%$ (from 3.76 to 5.23). With flexibility at the margin and the possibility of fixed-term contracts (panel 2), this volatility is increased by almost $30 \%$ (from 3.76 to 4.90 ). This scenario, however, assumes a low conversion rate of $10 \%$. When this rate is larger, for example $50 \%$, then this volatility increases by $56 \%$ and reaches 5.86 (panel 3). The high sensitivity to $\iota$, however, decreases as $\iota$ rises further.

\begin{tabular}{|c|c|c|c|}
\hline \multicolumn{4}{|c|}{$\begin{array}{ll}\text { Table 4. } & \begin{array}{l}\text { Simulated volatility under different } \\
\text { scenarios of employment protection }\end{array} \\
\end{array}$} \\
\hline & $\overline{\sigma \sigma(J C)}$ & $\overline{\overline{\sigma(J D)}}$ & 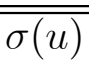 \\
\hline \multicolumn{4}{|l|}{ Panel 1: $\gamma^{T}=\gamma^{P}=\gamma, \iota=0$} \\
\hline$\gamma=0.00$ (Baseline case) & 3.76 & 4.58 & 5.40 \\
\hline$\gamma=0.025$ & 3.91 & 4.18 & 5.61 \\
\hline$\gamma=0.05$ & 4.19 & 3.72 & 5.66 \\
\hline$\gamma=0.10$ & 4.79 & 2.75 & 5.34 \\
\hline$\gamma=0.15$ & 5.23 & 1.71 & 4.63 \\
\hline \multicolumn{4}{|l|}{ Panel 2: $\gamma^{T}=0.00, \iota=0.10$} \\
\hline$\gamma^{P}=0.025$ & 3.98 & 4.77 & 5.67 \\
\hline$\gamma^{P}=0.05$ & 4.21 & 4.96 & 5.96 \\
\hline$\gamma^{P}=0.10$ & 4.61 & 5.29 & 6.57 \\
\hline$\gamma^{P}=0.15$ & 4.90 & 5.56 & 7.12 \\
\hline \multicolumn{4}{|l|}{ Panel 3: $\gamma^{T}=0.00, \gamma^{P}=0.15$} \\
\hline$\iota=0.05$ & 4.22 & 4.95 & 6.11 \\
\hline$\iota=0.10$ & 4.90 & 5.56 & 7.12 \\
\hline$\iota=0.50$ & 5.86 & 5.96 & 8.18 \\
\hline$\iota=1.00$ & 5.80 & 5.75 & 8.15 \\
\hline
\end{tabular}

The main intuition under these results is along the lines of Mortensen and Nagypal (2007) and Silva and Toledo (2007). According to the former, the presence of firing costs and other fixed labor turnover costs makes firms' net payoffs (that is, once subtracted these costs) more responsive to variations in the level of aggregate labor productivity. Silva and Toledo (2007), in turn, argue that firing costs reduce the firms' value of the match thereby generating discontinuous and abrupt adjustments on the job creation margin. These two works develop matching models similar to the one presented above, but with an important difference. They consider constant separation rates so that the labor market's behavior is entirely driven by the job creation rate. 
Firing costs reduce the value of the newly filled positions which becomes more sensitive to labor productivity shocks. In response to the wider variation in the value of new jobs there is a larger fluctuation in the number of vacancies that increases the volatility of the $\mathrm{JC}$ rate. The fact that this rate is relatively more volatile with a larger conversion rate implies that, the more restricted the duration of a temporary contract, the more sensitive is the job creation process to productivity shocks. In other words, a more stringent legislation on temporary jobs, make firms perceive good times as even better times so that they are more prone to open vacancies relative to the case of a labor market without these type of contracts.

In contrast to the response of the JC rate, the cyclical behavior of the job destruction rate (JD) differs across scenarios (column 2 in Table 4). With employment protection and no temporary contracts (panel 1), a rise in firing costs from $0 \%$ to $15 \%$ reduces the volatility of the JD rate by more than 3.5 times (from 4.58 to 1.71). The opposite occurs when firms are allowed to use fixed-term contracts: with flexibility at the margin (panel 2), it increases by $21 \%$ (from 4.58 to 5.56). Further, when the conversion rate from temporary to permanent workers moves from $10 \%$ to $50 \%$, the JD volatility has an additional increase of $7 \%$ (panel 3). As before, additional rises in $\iota$ generate smaller marginal responses in the JD volatility.

The first response is a well known result in the literature. The higher the firing costs, the more expensive becomes shedding workers. In this event firms tend to reduce their job destruction rate and make it less sensitive to shocks. New empirical evidence has been recently provided by Messina and Valanti (2007) for a set of 14 European countries and firm level data. They find that firms facing tight firing restrictions smooth job destruction over the business cycle.

This response, however, changes dramatically when firms are allowed to have flexibility at the margin. To avoid incurring in firing costs, they will make use of fixed-term contracts which will be more intensive the higher the separation tax on permanent workers. Moreover, in case of having to face restrictions in terms of the duration and number of renewals of fixed-term contracts, firms will find it optimal to further increase their labor turnover as a way to avoid transitions to a permanent status, which entails future costs in case of adjustments. In particular, before converting fixed-term contracts, they will hire another temporary worker and start the process again. In short, in response to productivity shocks, a situation of flexibility at the margin with restrictions generates a large volatility in the JD rate. Of course, this happens just up to a certain threshold (placed at a conversion rate of $50 \%$ in our analysis), which is plausible given that firms need a core set of stable workers. ${ }^{6}$

Finally, as a summary measure of the responses via JC and JD we assess the changes in the unemployment rate volatility (third column in Table 4). One of the new insights of

\footnotetext{
${ }^{6}$ Dolado, García-Serrano and Jimeno (2002), for example, refer to a steady-state level of the temporary share in Spain, which they place at a third of the dependent employment. The rest, thus, is the core set of stable workers needed by firms.
} 
our analysis is that, in the absence of flexibility at the margin (panel 1), unemployment fluctuations display a nonlinear relationship with respect to changes in the firing tax rates. This is the outcome of the movements, in opposite directions, of the standard deviations of the JC and JD rates. For low firing tax rates (up to 5\%), the JC volatility magnifying effects surpass the JD compressing effects and the volatility of unemployment increases by $6 \%$ (from 5.40 to 5.66). This positive effect is well known from the works by Mortensen and Nagypal (2007) and Silva and Toledo (2007). However, after some threshold in the gap of firing costs, which in our case is $5 \%$, higher firing taxes prompt a change in the relationship between unemployment volatility and employment protection. In particular, when $\gamma$ is beyond $5 \%$ the JD volatility reduction exceeds the increase in the standard deviation of the $\mathrm{JC}$ rate and generates a decline in unemployment volatility. Notice that the net effect for $\gamma=10 \%$ is virtually neutral (from 5.40 to 5.34 ).

When the labor market is characterized by employment protection on the permanent workers' side, but with the possibility of hiring on a fixed-term basis (panel 2), the unemployment rate volatility displays an unanimous positive association with the gap in the firing costs of these two type of workers. In particular, when the firing tax rate (and thus the gap) is shifted from $0 \%$ to $15 \%$, this volatility increases by $32 \%$ (from 5.40 to 7.12 ). Moreover, when the effects of the restrictions that bind the use of the temporary contracts are more stringent, it is further enhanced by $15 \%$ (from the former 7.12 when $\iota=0.10$, to 8.18 with $\iota=0.50)$. Again, this is true up to some threshold value, after which higher values of the conversion rate $\iota$ have very low incidence on firms' hiring decisions.

\subsection{Employment protection and job reallocation}

Let us now get back to Messina and Valanti's (2007) study on the impact of firing restrictions on job flow dynamics. They provide evidence that firms with tight firing restrictions smooth job destruction over the business cycle so that job turnover becomes less countercyclical. This is a result in line with previous studies that suggests an acyclical behavior of the labor flows in Continental Europe in contrast with their countercyclical pattern in the AngloSaxon countries (see Garibaldi, 1998).

However, Messina and Valanti also find some empirical evidence suggesting that the presence of temporary contracts may counter-balance the positive effect of the EPL on the cyclical behavior of job reallocation $(J R)$, which is the sum of job creation and job destruction (that is, $J R=J C+J D$ ). More specifically, they find a significant negative correlation between job reallocation and the business cycle in Spain, which is one of the countries with the most stringent EPL (see Table 1 in Messina and Valanti, 2007). In view of this counter-balancing effect via temporary contracts, they further estimate the incidence of fixed-term contracts on the cyclical behavior of JR with no success. According to their reasoning, a possible reason behind the absence of a significant relationship between these 
variables is that temporary contracts only affect the cyclicality of job flows through its complementarity with employment protection.

This possibility is the one we explore next. In particular, we ask our model to what extent the coexistence of EPL in permanent contracts with flexibility at the margin has a relevant incidence on JR. We measure this incidence with the correlation between the JR and the business cycle.

The answer is provided in Table 5 where, again, we distinguish three stylized cases: (i) a pure deregulated market, where $\gamma^{P}=\gamma^{T}=\iota=0$; (ii) a regulated market with no temporary contracts, where $\gamma^{P}=\gamma^{T}=0.15$ and $\iota=0$; and (iii) a regulated market with restricted flexibility at the margin, where $\gamma^{T}=0, \gamma^{P}=0.15$ and $\iota=0.1$.

It is interesting to observe that in the first case, which we associate with the 'AngloSaxon type' labor market, there is an almost perfect negative correlation between JR and the business cycle (-0.95). Further, it is also noteworthy the quasi pro-cyclical correlation (0.27) obtained in a regulated market with no flexibility at the margin, which is traditionally associated with some Continental European labor markets, as in Garibaldi (1998). The results on these two cases would generally be consistent also with the evidence provided by Messina and Valanti (2007). The value added of this exercise, however, lies in the third case, where the use of fixed-term contracts is restricted. We associate this case with the flexibility-at-the-margin type of labor market defined in the introduction.

\begin{tabular}{|c|c|c|c|}
\hline \multicolumn{4}{|c|}{ Table 5. Simulated correlation between JR and the business cycle } \\
\hline \multirow[b]{2}{*}{$\operatorname{corr}\left(y_{t}, J R_{t}\right)$} & $\begin{array}{c}\text { Deregulated market } \\
\gamma^{T}=\gamma^{P}=0.00 \\
\iota=0\end{array}$ & $\begin{array}{c}\text { Regulated market } \\
\text { with no temporality } \\
\gamma^{T}=\gamma^{P}=0.15 \\
\iota=0\end{array}$ & $\begin{array}{c}\text { Regulated market with } \\
\text { restrictions in temporality } \\
\gamma^{T}=0.00, \gamma^{P}=0.15 \\
\iota=0.1\end{array}$ \\
\hline & -0.954 & 0.268 & -0.865 \\
\hline $\begin{array}{l}\text { To } \\
\text { res } \\
\text { reg } \\
\text { wit }\end{array}$ & $\begin{array}{l}\text { utput is equal to } y_{t} \\
\text { ively, the average id } \\
\text { jobs. As before, we } \\
\text { e smoothing param }\end{array}$ & $\begin{array}{l}A_{t} \bar{z}_{t}^{T} n_{t}^{T}+A_{t} \bar{z}_{t}^{P} n_{t}^{P}-c \\
\text { ncratic productivity sl } \\
\text { rend the generated da } \\
\text { is set equal to } 1600 .\end{array}$ & $\begin{array}{l}\text { where } \bar{z}_{t}^{T} \text { and } \bar{z}_{t}^{P} \text { are, } \\
\text { s across temporary and } \\
\text { sing the HP filter }\end{array}$ \\
\hline
\end{tabular}

As shown in Table 5, the large negative correlation between JR and the business cycle $(-0.87)$ resembles very much the one of the pure deregulated labor market. Given the underlying analysis, we interpret this result as evidence that flexibility at the margin is a sufficient device to achieve the quick adjustments and large volatilities that characterize the fully flexible labor markets. This finding is, thus, a clear expression of the contribution of our analysis to this important issue. 


\section{Conclusions}

This paper argues that segmented labor markets with flexibility at the margin may achieve similar volatilities than fully deregulated labor markets. This is important because most OECD countries seem to conform to these two broadly defined type of markets. On the one hand, the liberalized or Anglo-Saxon type is characterized by low levels of EPL in regular contracts and no restrictions in the use of temporary employment. On the other hand, what we call the flexibility-at-the-margin type features stringent EPL and limitations in the use of temporary contracts. The firms' response to these different institutional setups is in stark contrast: in the first case, there is an occasional use of temporary contracts whereas in the second one firms rely deeply on fixed-term employment. Irrespective of the firms' labor management strategies, the outcome in terms of the volatility of the labor market is similar.

We rationalize this outcome by developing a matching model with heterogenous workers. In the spirit of the insider-outsider theory, we distinguish between regular and fixed-term employees and focus the analysis on a twofold dimension of segmented labor markets. First, on the effects that the gap in firing costs among these two type of workers has on the volatility of the labor market. Second, on the additional effects that arise from restricting the use of fixed-term contracts in terms of their duration and maximum number of renewals.

The gap in firing costs reduces the value of new filled positions on account of the future costs that firms will face when some proportion of the new hired fixed-term workers becomes permanent. This lower value implies a larger sensitivity with respect to shocks, which generates a larger fluctuation in the amount of vacancies posted. Hence the rise in the volatility of the job creation process. The intuition behind the second effect is straightforward. To avoid compulsory transitions to a permanent status, which entail future costs in case of adjustments, it is optimal for the firms to fire the workers whose contract is about to be upgraded for legal reasons, at no cost, and start a new relationship far in time from the binding legal restrictions on the fixed-term contract. This increases the volatility of the job destruction process and, as a consequence, the unemployment rate becomes more sensitive to productivity shocks.

We find that the volatility of the job creation rate is positively associated with the three key aspects of the legislation emphasized by our model: its rise amounts to $39 \%$ when firing costs increases from $0 \%$ to $15 \%$, to $30 \%$ when non-restricted flexibility at the margin is allowed, and to $56 \%$ when the conversion rate from a temporary to a permanent contract is fixed at the level of $50 \%$. In contrast, the volatility of the job destruction rate declines by more than 3.5 times in the first case, but increases $21 \%$ in the second and $30 \%$ in the third.

These responses yield a new insight in the analysis of the legislative setup incidence on the volatility of the labor market: the change in the direction of the response in job destruction generates a non-linearity in the relationship of the unemployment volatility with the gap in separation costs. 
A final important result is the almost perfect negative correlation we find between job reallocation and the business cycle both in the Anglo-Saxon and the flexibility-at-the-margin labor market types. This result clarifies the analogous finding for Spain in Messina and Valanti (2007), that could not be confirmed for the rest of the countries in the context of their analysis. Our paper, in fact, provides the rationale for such a finding.

Let us finish by stating that the achievement of similar flexibility/volatility than fully deregulated markets without fully deregulating the labor market is not synonymous of success. The study of the consequences of 'flexibility at the margin' by no means implies that this a desirable feature. There are profound differences in these two types of labor market whose assessment lied beyond the scope of this paper but that, nevertheless, deserve utmost attention. Among them is the gap in productivity between temporary and permanent workers. ${ }^{7}$ Any economic strategy relying excessively on fixed-term employment may end up biased towards low profile industries, low paid jobs and, generally, have a poor productivity performance. Spain is a paradigmatic case but this is left for future research.

\section{References}

[1] Autor, D.H., W.R. Kerr and A.D. Kugler (2007): "Does Employment Protection Reduce Productivity? Evidence from the US", The Economic Journal, vol. 117 (521), pp. F189F217.

[2] Azariadis, C. and C.A. Pissarides (2007): "Unemployment dynamics with international capital mobility", European Economic Review, vol. 51, 1, pp. 27-48.

[3] Blanchard, O.J. and P. Diamond (1989): "The Beveridge Curve", Brookings Papers on Economic Activity, vol. 1, pp. 1-60.

[4] Blanchard, O.J. and A. Landier (2000): "The Perverse Effects of Partial Labor Market Reform: Fixed Term Contracts in France", The Economic Journal, vol. 112, 480, pp. F214-F244.

[5] Boeri, T. and P. Garibaldi (2007): "Two Tier Reforms of Employment Protection: A Honeymoon Effect?", The Economic Journal, vol. 117 (521), pp. F357-F385.

[6] Cahuc, P. and F. Postel-Vinay (2002): "Temporary jobs, employment protection and labor market performance", Labour Economics, vol. 9, 1, pp. 63-91.

[7] Dolado, J.J., C. García-Serrano and J.F. Jimeno (2002): "Drawing lessons from the boom of temporary jobs in Spain", The Economic Journal, vol. 112, 480, pp. F270-F295.

[8] Garibaldi, P. (1998): "Job Flow Dynamics and Firing Restrictions", European Economic Review, vol. 42, pp. 245-275.

[9] den Haan, W.J., G. Ramey and J. Watson, (2000): "Job Destruction and Propagation of Shocks", American Economic Review, vol. 90, 3, pp. 482-498.

\footnotetext{
${ }^{7}$ The impact of EPL on productivity has been recently studied in Autor et al. (2007) for the US. We believe this opens a new research avenue on the interaction of these two important determinants of the labor market performance.
} 
[10] Kugler, A., J.F. Jimeno and V. Hernanz (2002): "Employment consequences of restrictive permanent contracts: evidence from Spanish labor market reforms", IZA Discussion Paper Series No. 657, IZA, Bonn.

[11] Lindbeck, A., and D.J. Snower (1989): The Insider-Outsider Theory of Employment and Unemployment, MIT Press.

[12] Malo, M.A. and L. Toharia (2000): "The Spanish experiment: pros and cons of flexibility at the margin", in Regini, M. and G. Esping-Andersen (eds.), De-regulation and Unemployment: the European Experience, Oxford, Oxford University Press, pp. 307-335.

[13] Messina, J. and G. Valanti (2007): "Job Flow Dynamics and Firing Restrictions: Evidence from Europe", The Economic Journal, vol. 117, 521, pp. 279-301.

[14] Mortensen, D.T and C.A. Pissarides (1994): "Job Creation and Job Destruction in the Theory of Unemployment", Review of Economic Studies, vol. 61, pp. 397-415.

[15] Mortensen, D.T. and C.A. Pissarides (1999) : "New Developments in Models of Search in the Labor Market", in O. Ashenfelter and D. Card (eds.), Handbook in Labor Economics, Amsterdam: North Holland.

[16] Mortensen, D.T. and E. Nagypal (2007): "More on unemployment and vacancy fluctuations", Review of Economic Dynamics, vol. 10, 3, pp. 327-347.

[17] OECD (2002): "Taking the measure of temporary employment", OECD Employment Outlook 2002, Paris, pp. 127-185.

[18] OECD (2004): "Employment Protection Regulation and Labour Market Performance", OECD Employment Outlook 2004, Paris, pp. 61-123.

[19] OECD (2006): "Employment and Labour Market Statistics", vol. 2006, release 01.

[20] Osuna, V. (2005): "The Effects of Reducing Firing Costs in Spain: A Lost Opportunity?", Contributions to Macroeconomics, vol. 5, 1, Article 5.

[21] Shimer, R. (2005): "The Cyclical Behavior of Equilibrium Unemployment and Vacancies", American Economic Review, vol. 95, 1, pp. 25-49.

[22] Silva, J.I. and M. Toledo (2007): "Labor Turnover Costs and the Cyclical Behavior of Vacancies and Unemployment", mimeo.

[23] Wasmer, E. (1999): "Competition for jobs in a growing economy and the emergence of dualism in employment", The Economic Journal, vol. 109, 457, pp. 349-371. 